\title{
Learning mediates the exposure-attraction relationship: More evidence
}

\author{
DAVID J. STANG \\ American Psychological Association, 1200 Seventeenth Street, N. W., Washingtom, D.C. 20036 \\ JOSEPH FARANDA \\ University of Delaware, Newark, Delaware 19711 \\ and \\ JOHN TANTILLO \\ Hofstra University, Hempstead, New York 11550
}

\begin{abstract}
Previous research has suggested that repeated exposure to novel stimuli produces changes in their connotative meaning, but that some delay may be required for this effect. Thirty-six undergraduates viewed nonsense syllables in various frequencies, then rated them for pleasantness following no delay (Condition 1) or following a delay which provided cognitive activity presumably facilitating or inhibiting rehearsal (Conditions 2 and 3). In all three conditions, both judged pleasantness and recall were a linear increasing function of log exposure frequency; no main effect of condition nor interaction of Condition by Frequency was found. The results suggest a rating delay may not always be needed for "mere exposure" effects.
\end{abstract}

Recently, Stang (1975) presented evidence that learning mediates the relationship between exposure frequency and attraction: Repeated exposure to novel stimuli results in learning; learning leads to liking. One analysis of the previous literature (Stang, 1974b) suggests that repeated exposure is most likely to lead to more positive evaluations when there is a delay between exposure and rating. Possibly during a delay, rehearsal and consolidation occur proportionally to exposure frequency, explaining why two previous studies (Hellyer, 1962; Stang, 1975) found no relationship between exposure frequency and recall with no delay, the usual relationship with a brief delay. If rehearsal or other cognitive activity is needed during the delay, then interference with this activity during the delay should produce a similar effect for a no-delay condition.

\section{METHOD}

Thirty-six undergraduate male and female students were each randomly assigned to one of three experimental conditions. In all three conditions, participants silently viewed 10 Turkish words during an exposure phase; during a rating phase, subjects rated these 10 words and 2 new ones for pleasantness, and then attempted to recall the words seen.

The 12 Turkish words were exposed in the frequencies of $0,1,2,5,10$, and 25 occurrences, counterbalanced across subjects. Words were printed on index cards, the proper combina-

Results presented here have been presented at the annual meeting of the APA, Washington, D.C., September 1976. Requests for reprints should be sent to David Stang, American Psychological Association, 1200 17th Street, NW, Washington, D.C. 20036. tion of frequencies for a participant was selected, and the deck shuffled. During the exposure phase, the participant viewed each card for $3 \mathrm{sec}$, with effectively no interstimulus interval.

During the rating phase, participants rated all 12 words in a constant order on a 7-point pleasant-unpleasant scale, anchored with the quantifiers "extremely," "moderately," and "slightly." Participants were then requested to write down as many of the 12 words as they could recall, and finally went through a careful postexperimental inquiry to assess possible subject expectancy effects (Stang, 1974a).

The three conditions differed only in the events occurring between exposure and rating phases. In the no-delay condition, there was no separation of exposure and rating phases. In the delay-counting condition, subjects were required to count aloud backward by threes from 1,000 for $5 \mathrm{~min}$; in the delay-thinking condition, subjects were requested to think about the words they had seen during the exposure phase for $5 \mathrm{~min}$. Delay counting was expected to impede rehearsal and recall, while delay thinking was expected to enhance rehearsal and recall.

\section{RESULTS}

A 3 (conditions) by 6 (exposure frequencies) ANOVA with repeated measures on the second factor was done on mean recall probability of each pair of words at each frequency. While there was a strong effect of frequency on recall $[F(5,165)=27.8, p<.01]$, there were no differences between conditions $[F(2,165)$ $=1.44$, n.s.] nor an interaction of Condition by Frequency $[F(10,165)=1.11$, n.s.] . The two-factor theory (Stang, 1975) would predict similar effects for judged pleasantness, as was the case: There was a main effect of frequency on pleasantness $[\mathrm{F}(5,165)=15.1, \mathrm{p}<.01]$ but no difference between conditions $[F(2,165)=2.51$, n.s.] nor an interaction of Condition by Frequency 
$[F(10,165)=.71$, n.s. $]$. Judged pleasantness increased as an approximately linear function of $\log$ exposure frequency, being $3.49,3.36,4.04,4.32,4.70,5.15$ on the 1-7 scale for the frequencies $0,1,2,5,10,25$, respectively. Recall probability similarly increased for the six frequencies, being $.08, .06, .25, .35, .45, .72$, respectively. The logarithm of exposure frequency accounted for slightly more variance in judged pleasantness $(80 \%)$ and recall $(88 \%)$ than did the optimal combination of the first, second, and third powers of exposure frequency.

On the basis of their postexperimental inquiry guesses as to the purpose of the experiment, respondents were separated and their pleasantness judgments and recall scores for the six frequencies compared by ANOVA. No main effects of subject intuitions on these dependent measures were found, nor were there interactions of intuition with exposure frequency on recall or judged pleasantness.

Multiple regression using exposure frequency and recall to predict judged pleasantness supports the hypothesis that learning mediates in the relationship between exposure and attraction $(R=.93$; recall beta $=$ $1.04, \mathrm{~F}=22.9$; frequency beta $=-.12, \mathrm{~F}=.34$ ), although multicollinearity problems may overemphasize the relative importance of recall.

\section{DISCUSSION}

Although the results obtained in the present study are consistent with the two-factor theory, two other theoretical questions are raised. First, why did similar functions occur in all three conditions? Possibly the relatively long exposure interval $(3 \mathrm{sec})$ enabled adequate rehearsal and consolidation during the exposure phase, so that additional delay had no further benefit on the frequency-recall relationship. Such an explanation could be tested by providing interference during the exposure phase, as Kreindler and Hakmiller (Note 1) have done.

The absence of subject expectancy effects, while strengthening the present results, adds some further confusion to the intuition-as-artifact hypothesis (Stang, 1974a), as have a number of recent studies in this area (Marcus, Note 2; Wilson, Note 3). Perhaps the adequacy of the cover story, the general sophistication of subjects, or other variables are responsible for different results in different experiments.

\section{REFERENCE NOTES}

1. Kreindler, M., \& Hakmiller, K. Mere interference and attitudes. Paper presented at the annual meeting of the American Psychological Association, Washington, D.C., 1976.

2. Marcus, M. G. Some thoughts on a failure to replicate. Paper presented at the annual meeting of the American Psychological Association, Washington, D.C., 1976.

3. Wilson, W. R. The unobtrusive induction of positive attitudes. Unpublished doctoral dissertation. University of Michigan, 1975.

\section{REFERENCES}

Hellyer, S. Supplementary report: Frequency of stimulus presentation and short-term decrement in recall. Journal of Experimental Psychology, 1962, 64, 650.

STANG, D. J. Intuition as artifact in mere exposure research. Journal of Personality and Social Psychology, 1974, 30, 647-653. (a)

Stang, D. J. Methodological factors in mere exposure research. Psychological Bulletin, 1974, 81, 1014-1025. (b)

StANG, D. J. Effects of "mere exposure" on learning and affect. Journal of Personality and Social Psychology, 1975, 31, 7-12.

(Received for publication August 12, 1976.) 